\title{
Roxane Martin, L'Émergence de la notion de mise en scène dans le paysage théâtral français (1789-1914)
}

\section{Mariette Delamaire}

\section{(2) OpenEdition}

1 Journals

\section{Édition électronique}

URL : http://journals.openedition.org/studifrancesi/1357

DOI : 10.4000/studifrancesi. 1357

ISSN : 2427-5856

Éditeur

Rosenberg \& Sellier

\section{Édition imprimée}

Date de publication : 1 décembre 2015

Pagination : 595-597

ISSN : 0039-2944

\section{Référence électronique}

Mariette Delamaire, «Roxane Martin, L'Émergence de la notion de mise en scène dans le paysage théâtral français (1789-1914)", Studi Francesi [En ligne], 177 (LIX | III) | 2015, mis en ligne le 01 décembre 2015, consulté le 07 janvier 2021. URL : http://journals.openedition.org/studifrancesi/1357 ; DOI : https:// doi.org/10.4000/studifrancesi. 1357

Ce document a été généré automatiquement le 7 janvier 2021.

\section{(c) $(1) \odot$}

Studi Francesi è distribuita con Licenza Creative Commons Attribuzione - Non commerciale - Non opere derivate 4.0 Internazionale. 


\title{
Roxane Martin, L'Émergence de la notion de mise en scène dans le paysage théâtral français (1789-1914)
}

\author{
Mariette Delamaire
}

\section{RÉFÉRENCE}

ROXANE MARTIN, L'Émergence de la notion de mise en scène dans le paysage théâtral français (1789-1914), Paris, Classiques Garnier, 2013, pp. 257.

1 Pourquoi et comment la mise en scène s'est-elle développée au cours du XIX ${ }^{e}$ siècle jusqu'à aujourd'hui, où elle a une position primordiale? Roxane Martin s'attache à «l'émergence» d'une «notion», c'est-à-dire à un processus lent qui part d'une pratique, la mise en scène, pour aboutir à la reconnaissance d'un métier, dans une période et un espace délimités: dans «le paysage théâtral français» entre 1789 et 1914, depuis la représentation de Charles IX de Marie-Joseph Chénier jusqu'à la fin de la direction d'Antoine à l'odéon.

2 Le «paysage théâtral français», expression qui couvre Paris et la province, permet d'étudier, outre le texte dramatique, tout ce qui concourt à produire un spectacle: les conditions physiques de la représentation, l'architecture du théâtre, la chorégraphie, les décors, la musique, l'organisation des troupes (directeurs et comédiens), le rôle joué par les autorités politiques, et ce qui relève de la réception par le spectateur ou la critique.

3 L'ouvrage se divise en quatre parties qui suivent les grandes évolutions de l'histoire du théâtre: de la Révolution au décret de 1807 qui rétablit les privilèges dramatiques; de 1807 à 1829 où la fonction de metteur en scène prend son essor grâce au mélodrame; de 1830 à 1864 , extension du drame romantique; enfin de la fin des privilèges dramatiques, en 1864, à 1914. 
4 Le premier chapitre rappelle que la suppression des privilèges dramatiques et la reconnaissance du droit d'auteur en 1791 entraînent la prolifération des théâtres et l'élargissement à un public populaire du répertoire classique. Pièces de circonstances ou chefs-d'œuvre du passé, il convient qu'ils deviennent immédiatement accessibles au public, grâce à la convergence de tous les éléments scéniques: le texte, parfois récrit pour lui donner «un accent prophétique», devient une sorte de matériau scénique parmi d'autres. Le désir de propagation des idées révolutionnaires au moyen des fêtes, qui associent le spectateur autour des «éléments scéniques», crée ce que Roxane Martin désigne par «un langage scénique innovant». La Montagne, puis le Directoire, suivirent la même politique culturelle: «façonner l'esprit public», exercer une stricte surveillance sur les théâtres, lieux de rassemblement populaire. La reprise par les censeurs de l'autorité sur les spectacles favorise l'amplification des didascalies et le développement de la mise en scène qui doit exprimer l'interprétation: c'est sous le Directoire que se banalise l'emploi du mot «mise en scène».

5 L'excellent deuxième chapitre montre comment le mélodrame, dont l'apogée se situe sous l'Empire et les premières années de la Restauration, a joué un rôle décisif dans la notion de la mise en scène comme créateur du spectacle autant et même parfois plus que le texte. Le décret de 1807, qui revient aux formes de l'Ancien Régime, marque un recul mais n'annule pas les acquis de la Révolution. Les réformes subsistent au sein du mélodrame, genre nouveau, qui combine dans une structure codifiée musique, texte, pantomime, effets spéciaux, alternance de mouvement et d'immobilité, pour produire un spectacle «à fonction cathartique»: «le mélodrame transmue un monde injuste en une société fondée sur le triomphe de la vertu» (p. 64). Le public préfère aux «grands genres» des scènes officielles, les genres secondaires du vaudeville et du mélodrame. Dans cette deuxième partie, R. Martin, qui dirige l'édition critique des Mélodrames de Pixerécourt, démontre l'influence capitale du mélodrame, et singulièrement celle de Pixerécourt, sur le changement du rôle du metteur en scène: il exigea des théâtres de province que les pièces fussent montées selon les indications de la brochure publiée, ce qui les amena à engager un directeur de la scène. L'évolution du mélodrame vers le drame historique introduit un souci de réalisme favorisé par des innovations techniques dans la construction des théâtres (éclairage au gaz, profondeur de scène accrue, éclairage latéral, technique du panorama et du diorama). Ces innovations qui font du peintre-décorateur l'élément central de la représentation, l'influence du jeu réaliste des comédiens anglais qui interprètent Shakespeare, apportent «un renouvellement dans la posture, la mimique, les déplacements et le maquillage de l'acteur» (p. 86). À partir de 1825, le baron Taylor introduira au Théâtre-Français l'expérience acquise dans le mélodrame, et toutes les scènes officielles auront un directeur de la scène à la fin de la Restauration.

Cette rupture esthétique ouvre la voie au théâtre romantique, objet du troisième chapitre: «La mise en scène ou le brouillage des catégories génériques (1830-1864)». R. Martin récuse la périodisation traditionnelle qui clôt l'histoire du drame romantique sur Les Burgraves en 1843. Elle prolonge l'étude de la mise en scène romantique jusqu'en 1864 quand l'abolition définitive des privilèges dramatiques rompt la distinction entre les scènes officielles et les théâtres du boulevard. Le théâtre romantique semble aussi difficile à définir que le romantisme lui-même des Lettres de Dupuis et Cotonet. R. Martin estime que c'est la mise en scène qui assure l'unité esthétique. Le drame romantique, social ou historique, s'empare des codes scéniques du mélodrame tout en les utilisant à 
ses propres fins, mélange des genres, mélange entre les théâtres officiels et ceux du boulevard, mélange des publics. La dramaturgie est chargée de manifester la dimension sociale et politique du théâtre. Mais la critique se trouve divisée: si elle admet que les genres visuels comme le ballet, la féerie, le cirque ou la pantomime exigent une mise en scène spectaculaire, en revanche elle la blâme pour le drame, la tragédie ou la comédie, et surtout au sujet de la mise en scène des chefs-d'œuvre du répertoire classique.

7 Le quatrième chapitre, «Le matériel et l'immatériel. 1865-1914», examine les changements importants qui découlent de la liberté accordée aux théâtres. L'abolition des privilèges dramatiques accroît la concurrence entre les théâtres. Soucieux de rentabilité, les directeurs cherchent le succès en engageant des acteurs célèbres et en donnant davantage de responsabilités au metteur en scène dont le «métier» se met en place: il doit à lui seul élaborer le spectacle, diriger les acteurs et produire le travail d'interprétation. Mais il échoue à la fin du siècle à se faire reconnaître juridiquement comme artiste et créateur. Contre les goûts du public qui le portent vers les spectacles à la mise en scène coûteuse, certains appellent à une réforme théâtrale afin de maintenir un théâtre "d'art», un théâtre populaire, en opposition avec un théâtre mercantile. L'ambition d'Antoine au Théâtre Libre est d'élargir le public et de s'affranchir des contraintes économiques, de la censure et de la Société des auteurs et compositeurs dramatiques. L'esthétique de la scène qu'il expose dans sa célèbre Causerie de 1903 sera introduite ensuite sur les théâtres subventionnés. C'est dans le répertoire classique qu'Antoine a apporté, une fois directeur de l'Odéon, de véritables réformes: il s'agit de «bouleverser le spectateur afin de l'engager à réfléchir autrement le monde contemporain» (p. 222). D'Antoine à Vilar, le problème de la mise en scène est crucial pour le répertoire classique: comment le jouer pour en faire jaillir le sens caché ou ignoré? Le développement du rôle du metteur en scène au cours $d u$ XIX ${ }^{e}$ siècle, puis la constitution de la mise en scène comme art indépendant conduisent à une réflexion plus globale sur les enjeux politiques et sociaux du théatre. À la définition traditionnelle de la mise en scène comme «organisation matérielle de la représentation», R. Martin en substitue une nouvelle: «la mise en scène est un concept inventé de toute pièce pour réfléchir la relation entre une œuvre, un public et l'image qu'il se fait de son identité culturelle» (p. 224).

8 L'ouvrage de Roxane Martin apporte par son étendue, la variété des sources, son érudition, un regard nouveau sur l'histoire du théâtre au xIx siècle, étudié à partir du spectaculaire: que veut-on montrer au spectateur? En prenant le parti de considérer que le spectacle qui lui est proposé est le fruit d'un ensemble qui englobe un espace, des techniques et des praticiens de l'illusion, des musiciens, des danseurs, des acteurs, un metteur en scène, elle montre que le texte d'une pièce de théâtre n'en est qu'un élément, pas toujours le principal, et que, loin d'être fixe, il est sujet à reprises, réinterprétations, renouvellement. Elle en vient alors à envisager le spectacle comme formé d'un triangle: auteur, éléments scéniques, spectateur. À partir de ce triangle, s'élabore une histoire qui place le metteur en scène au centre: c'est lui qui révèle le sens, c'est lui qui établit la communion entre la scène et le spectateur. Ce rôle de créateur et de constitution d'un "démos régi par une identité culturelle commune» (p. 226) lui semble mis en question aujourd'hui par la multiplicité des réalisateurs d'une œuvre dramatique, la circulation mondiale des œuvres sur internet, le rôle nouveau donné au "consommateur/lecteur/spectateur», chargé à son tour de donner sens et unité, là où il n'y a que disparate et informe. Le livre s'achève donc sur cette question 
paradoxale: la mise en scène est-elle en train de disparaître? En reprenant des discussions récentes, l'A. ouvre alors des perspectives qui, faute d'exemples, laissent le lecteur en proie à ses questions.

9 Cette étude comprend un grand nombre de notes érudites, références, exemples, biographies, une bibliographie copieuse et un index des noms qui rendent aisée une recherche par le lecteur. Le style et la mise en pages sont généralement clairs. Il est d'autant plus à regretter quelques coquilles et de surprenantes négligences d'expression («générer» p. 10 et p. 139, «réformes initiées» pp. 53, 86, et 210, «fonctions... renseignées» p. 121, «actées», p. 122). Néanmoins, cet ouvrage demeurera indispensable à tous les historiens du théâtre comme à ceux qui s'interrogent sur son avenir. 